\title{
BMJ Open Evaluating Midwifery Units (EMU): a prospective cohort study of freestanding midwifery units in New South Wales, Australia
}

\author{
Amy Monk, ${ }^{1}$ Mark Tracy, ${ }^{2}$ Maralyn Foureur, ${ }^{3}$ Celia Grigg, ${ }^{1}$ Sally Tracy ${ }^{4}$
}

To cite: Monk A, Tracy M, Foureur M, et al. Evaluating Midwifery Units (EMU): a prospective cohort study of freestanding midwifery units in New South Wales, Australia. BMJ Open 2014;4: e006252. doi:10.1136/ bmjopen-2014-006252

- Prepublication history and additional material is available. To view please visit the journal (http://dx.doi.org/ 10.1136/bmjopen-2014006252).

Received 29 July 2014 Revised 26 September 2014 Accepted 13 October 2014

CrossMark

For numbered affiliations see end of article.

Correspondence to Amy Monk;

amy.monk@sydney.edu.au

\section{ABSTRACT}

Objective: To compare maternal and neonatal birth outcomes and morbidities associated with the intention to give birth in two freestanding midwifery units and two tertiary-level maternity units in New South Wales, Australia.

Design: Prospective cohort study.

Participants: 494 women who intended to give birth at freestanding midwifery units and 3157 women who intended to give birth at tertiary-level maternity units. Participants had low risk, singleton pregnancies and were at less than $28^{+0}$ weeks gestation at the time of booking.

\section{Primary and secondary outcome measures:}

Primary outcomes were mode of birth, Apgar score of less than 7 at 5 min and admission to the neonatal intensive care unit or special care nursery. Secondary outcomes were onset of labour, analgesia, blood loss, management of third stage of labour, perineal trauma, transfer, neonatal resuscitation, breastfeeding, gestational age at birth, birth weight, severe morbidity and mortality.

Results: Women who planned to give birth at a freestanding midwifery unit were significantly more likely to have a spontaneous vaginal birth (AOR 1.57; $95 \% \mathrm{Cl} 1.20$ to 2.06 ) and significantly less likely to have a caesarean section (AOR $0.65 ; 95 \% \mathrm{Cl} 0.48$ to 0.88 ). There was no significant difference in the AOR of 5 min Apgar scores, however, babies from the freestanding midwifery unit group were significantly less likely to be admitted to neonatal intensive care or special care nursery (AOR 0.60; $95 \% \mathrm{Cl} 0.39$ to 0.91 ). Analysis of secondary outcomes indicated that planning to give birth in a freestanding midwifery unit was associated with similar or reduced odds of intrapartum interventions and similar or improved odds of indicators of neonatal well-being.

Conclusions: The results of this study support the provision of care in freestanding midwifery units as an alternative to tertiary-level maternity units for women with low risk pregnancies at the time of booking.

\section{INTRODUCTION}

In New South Wales, the most populous state in Australia, most babies are born in a

\section{Strengths and limitations of the study}

- This is the first prospective cohort study of maternal and neonatal outcomes of women who planned to give birth in freestanding midwifery units compared with women who planned to give birth in tertiary-level maternity units in Australia.

- Selection bias was minimised by prospectively identifying women's planned place of birth at booking and analysing the outcomes according to the place where women intended to give birth. The population database ensured that there was a minimal loss to follow-up and minimal bias introduced due to a non-response rate.

- The study ensured comparability of the cohorts of women by evaluating risk at booking and controlling for confounding factors including risk at the onset of labour. However, subtle differences may exist between women who plan to give birth in different settings, and these differences cannot be quantified. Also, socioeconomic status and body mass index could not be controlled and may have had a confounding effect on the outcomes.

- This study was not powered to detect clinically significant differences in perinatal mortality. Meaningful conclusions on longer term perinatal outcomes could not be drawn from the datasource.

hospital setting. Of the 96489 recorded births in 2010, $246(0.3 \%)$ babies were born at home, $468(0.5 \%)$ babies were born before arrival to the hospital and 95775 (99.3\%) babies were born in a hospital maternity unit. ${ }^{1}$ Contemporary hospital maternity services differ from each other considerably. The two hospital maternity services at opposite ends of the spectrum in terms of context and system of care are freestanding midwifery units and tertiary-level maternity units. There are major gaps in the evidence associated with giving birth in these different settings.

Tertiary-level maternity units offer care by specialist obstetricians and midwives. They cater for all pregnant women, regardless of risk 
status, and are the most appropriate place for women with complex and/or rare problems to give birth. Specialist obstetric, anaesthetic and paediatric consultation is available $24 \mathrm{~h}$ a day. ${ }^{23}$ Some tertiary-level maternity units have integrated alongside birth centres that have a home-like environment and offer a midwiferymanaged model of care to women at low risk of obstetric complication. ${ }^{4}$

Freestanding midwifery units provide a unique system of care to Australian women who have no identified risk factors and who either choose not to give birth at, or have limited access to other types of maternity care. They are unique in the Australian context because they offer primary level care by a named midwife and have no routine involvement of medical staff. They are also geographically separate from facilities offering onsite obstetric, paediatric or specialised medical consultation and procedures including epidural analgesia and caesarean section. ${ }^{25}$

New South Wales' maternity policy strongly supports tertiary-level maternity care for all women. ${ }^{6-11}$ Planning to give birth at a facility without on-site specialist medical support is largely perceived as hazardous and unsafe for women and their unborn babies. ${ }^{6}{ }^{12}$ Consequently, there were only two freestanding midwifery units in New South Wales (and in Australia) in 2005, recording a combined total of approximately 300 births, ${ }^{13} 14$ compared with seven tertiary-level maternity units with 25637 births. ${ }^{15}{ }^{16}$ It is unknown whether the actual gains match the expected gains of concentrating all low-risk births in large tertiary hospitals. ${ }^{5} 1718$

Robust international evidence has recently been published to evaluate the safety and cost-effectiveness of planning to give birth at freestanding midwifery units for women with low-risk pregnancies. ${ }^{19-23}$ A landmark prospective cohort study by the Birthplace in England Collaborative Group ${ }^{19}$ found that there was no significant difference in rates of perinatal mortality or morbidities relating to intrapartum events between women who planned to give birth in freestanding midwifery units compared with those who planned to give birth in tertiary obstetric units (AOR 0.92; 95\% CI 0.58 to 1.46). Furthermore, women who planned to give birth in the freestanding units were less likely to have a ventouse delivery (AOR 0.32; 95\% CI 0.22 to 0.47), forceps delivery (AOR 0.45 , 95\% CI 0.32 to 0.63 ), intrapartum caesarean section (AOR 0.32, 95\% CI 0.24 to 0.42) or syntocinon augmentation (AOR 0.26 ; $95 \%$ CI 0.20 to 0.33 ) than women who planned to give birth at a tertiary obstetric hospital.

Despite these findings, freestanding midwifery units remain a scarce model of maternity care in Australia. This is likely to remain the case without robust Australian research that evaluates their safety.

\section{Objectives}

The Evaluation of Midwifery Units study was a prospective cohort study that aimed to fill in some of the gaps in current research evidence on giving birth in freestanding midwifery units compared with tertiary-level maternity units. It was undertaken in two Area Health Services in New South Wales, Australia and in one District Health Board in New Zealand. The aim was to compare the maternal and neonatal birth outcomes and morbidities associated with the 'intention to give birth' or 'booking at' the freestanding midwifery units in each health district compared with a reference cohort booked at the tertiary referral maternity hospitals integrated with the freestanding midwifery units. This paper reports the findings from the Australian arm of the study.

The researchers have adhered to the STROBE statement for improving the quality of the reporting of observational studies. ${ }^{24}$

\section{METHODS \\ Setting}

Two freestanding midwifery units in regional and urban areas of New South Wales participated in the study. The most recent published data on the volume of births in the participating units (which were the only FMUs in Australia at the time) is from 2005/2006, when 326 births were recorded over a 12-month period. ${ }^{13} 14$ Women receive antenatal, intrapartum and postnatal care from their midwifery group practice midwives. These midwives work in small groups and provide $24 \mathrm{~h}$ on-call midwifery care. If the need for transfer to the referral tertiary-level maternity unit arises, the midwifery group practice midwife often, but not always, transfers with the woman and continues to provide midwifery care in the tertiary unit. ${ }^{25}$ The referral tertiary-level maternity units are approximately $15-20 \mathrm{~km}$ away from the freestanding midwifery units; and transfer time may take between 15 and 65 min depending on traffic conditions. Intrapartum and postnatal transfers occur via car or ambulance depending on the urgency of the transfer.

The two tertiary-level maternity units used as comparators in this study were the tertiary referral hospitals formally recognised as the referral hospitals for the freestanding midwifery units described above. They recorded a combined total of 6072 births in $2010 .{ }^{1}$ They have a very wide catchment area, spanning 75 hospitals in New South Wales ${ }^{26}$ and receive women and babies transferred from all other maternity units in the catchment areas. Women receive antenatal, intrapartum and postnatal care from a number of models of care, including obstetric and midwifery antenatal clinics, general practitioner-shared care, birth centre and midwifery group practice. ${ }^{25}$

\section{Participants}

Women with low-risk singleton pregnancies were eligible to participate in the study if they were less than $28^{+0}$ weeks pregnant at the time of booking and planned to give birth at a participating maternity unit during the study period. 
Table 1 Australian College of Midwives (ACM) three levels of consultation and referral ${ }^{\star}$

ACM A-discuss
The woman's condition or situation
requires discussion with another
midwife or member of the healthcare
team to plan for optimal care.
Responsibility of care stays with the
midwife

ACM B-consult

The woman's condition or situation requires consultation with the medical practitioner, ideally in a 'face to face' consultation. Responsibility of care will either stay with the midwife or transfer to a medical practitioner
ACM C-refer

The woman's condition or situation requires temporary or ongoing medical care at a tertiary or secondary level. Responsibility of care is transferred to a medical practitioner

${ }^{*} \mathrm{ACM}$ occasionally uses levels interchangeably by categorising some conditions as $\mathrm{A} / \mathrm{B}$ or $\mathrm{B} / \mathrm{C}$. Level of referral is left to the discretion of the midwife, in consultation with the woman, and a medical practitioner if required.
The Australian College of Midwives (ACM) Guidelines for Consultation and Referral were used to identify low-risk women from the tertiary-level maternity unit cohort (table 1). Women were defined as low risk if they did not identify an ACM B/C or C risk factor at booking (table 2) ${ }^{27}$ Previous caesarean sections are not classed as an ACM category $\mathrm{B} / \mathrm{C}$ or $\mathrm{C}$ risk factor. Therefore women who had experienced a previous caesarean section were included in the study and "previous caesarean section' was controlled in the analysis.

All women booked to give birth at the freestanding midwifery units were considered low risk and were included in the study, regardless of their specific ACM risk classification. This was a pragmatic a priori decision taken at the beginning of the study. The rationale for this was that the midwifery and obstetric teams from the freestanding midwifery units in this study work collaboratively with women to ensure their suitability to give birth at the freestanding midwifery units. They use the ACM guidelines in conjunction with other information (such as detailed medical records and physical assessment) to determine with the women themselves whether they would be advised to proceed to give birth in a freestanding midwifery unit and, if necessary, when to transfer.

The two sample cohorts were further scrutinised to identify women with a risk at the onset of labour.
Women were defined as having a risk at the onset of labour if they developed any ACM B/C or $\mathrm{C}$ risk conditions during pregnancy that may have led to a higher risk of requiring medical or obstetric care during labour and birth (table 2). This enabled 'risk at the onset of labour' to be controlled in the analysis.

\section{Data collection}

Data custodians from each maternity unit used the ObstetriX database to identify eligible women who booked to give birth at the participating maternity units during the study period 1 April 2010 and 31 August 2011. ObstetriX is a statewide surveillance system used across New South Wales to provide point-of-care maternity data collection across the antenatal, intrapartum and immediate postnatal periods. Midwives contribute the data on each woman and her baby as soon after birth as is possible.

The primary outcome measures were mode of birth, 5 min Apgar score of less than 7 and admission to the neonatal intensive care unit (NICU) or special care nursery (SCN) from the time of birth to discharge. Secondary maternal outcomes included type of onset of labour, use of analgesia, rates of postpartum haemorrhage, management of third stage of labour, rates of perineal trauma, stage of transfer and severe morbidity. Secondary neonatal outcomes included the need to

Table $2 \mathrm{ACM} \mathrm{B/C}$ and $\mathrm{C}$ conditions constituting a risk at booking or at the onset of labour

\begin{tabular}{|c|c|}
\hline Type of risk & Description of $\mathrm{ACM} B / C$ and $\mathrm{C}$ conditions constituting a risk \\
\hline Booking & $\begin{array}{l}\text { Essential hypertension, renal disease, diabetes (not including gestational diabetes), adrenal disease, pituitary } \\
\text { disease, asthma, cardiomyopathy, congenital heart disease, heart murmur, myocardial infarction, congenital } \\
\text { renal disease, glomerulonephritis, antiphospholoid antibodies, rheumatoid antibodies, SLE, connective tissue } \\
\text { disease, epilepsy, benign intracranial hypertension, thromboembolism, platelet disorder, clotting disorder, } \\
\text { thalassaemia, organ transplant, neurological/spinal surgery*, classical caesarean section*, spina bifida*, } \\
\text { fibromyalgia*, spinal cord disease* or any cardiac condition*, myomectomy, bicornate uterus, eclampsia or } \\
\text { HELLP syndrome (haemolysis, elevated liver enzymes and low platelet count) }\end{array}$ \\
\hline $\begin{array}{l}\text { Onset of } \\
\text { labour }\end{array}$ & $\begin{array}{l}\text { Abnormal placental site, placenta praevia, placental abruption, eclampsia, preeclampsia, essential } \\
\text { hypertension, renal hypertension, insulin dependent gestational diabetes, pre-existing diabetes, any new } \\
\text { cardiac, endocrine, GIT, liver, gastrobiliary, haematological or infectious condition, pyelonephritis, uterine } \\
\text { anomaly } \\
\text { for cervical shorten renal/neurological conditions }{ }^{*} \text {, any fetal anomaly, threatened premature labour, admission } \\
\text { feticide, intrauterine transfusion, breech/transverse/oblique lie or preterm rupture of membranes }\end{array}$ \\
\hline
\end{tabular}

${ }^{*}$ These conditions were not listed in ACM guidelines, however, they were considered to be equivalent to $\mathrm{ACM} B / C$ and $C$ conditions.

ACM, Australian College of Midwives; GIT, gastrointestinal tract; SLE, systemic lupus erythaematosus. 
resuscitate, breastfeeding at birth and on hospital discharge, gestational age, birth weight, severe morbidity (defined as 5 min Apgar score of less than 7 followed by admission to NICU/SCN, restricted to live born babies greater than 24 weeks gestation) and neonatal mortality.

Data were collected from the ObstetriX database, except for a limited amount of transfer data which were collected from maternal medical records. Neonatal data on reason for NICU/SCN admission, treatment details and perinatal mortality and morbidity recorded in data bases other than the ObstetriX data base were not available for this study.

\section{Statistical analysis}

The study was powered to detect a clinically relevant fall of $21 \%$ in the rate of women requiring a caesarean section from $29 \%$ to $23 \%$, with $90 \%$ power and a significance level of $p=0.05$. These numbers were also sufficient to detect a clinically significant reduction of 4.0 percentage points in the rate of instrumental birth (forceps/ventouse) from $11 \%$ to $7 \%$ with $90 \%$ power and a significance level of $\mathrm{p}=0.05$. These differences were based on data available from the first report of birth outcomes at both freestanding midwifery units in the years preceding the study compared with statewide maternity data. ${ }^{13} 1416$

Analyses were by 'intention to treat' with outcomes attributed to planned place of birth at the time of booking. ORs with 95\% CIs were calculated for the primary and secondary outcomes. Measures of categorical data were analysed with $\chi^{2}$ tests and continuous data were analysed using the $\mathrm{t}$ test. Multivariate logistic regression was used for dichotomous outcomes to adjust for relevant known confounders. Adjustment was made for maternal age, smoking status, parity, risk at the onset of labour, previous caesarean section, gestation at the time of birth, induction and augmentation of labour where relevant. Socioeconomic status and body mass index (BMI) were unable to be controlled using the available data sources. Adjusting for ethnicity was complex due to the diverse ethnic groups represented in the sample; the individual ethnic groups were not found to have a confounding effect so were not included in the final analysis. Women who had an elective caesarean section were excluded when calculating the AORs for analgesia during labour. Women who had a caesarean section were excluded when calculating the AORs for perineal trauma. Neonatal outcomes for live born babies were adjusted for maternal age, smoking status, parity, augmentation, induction, previous caesarean section and risk at the onset of labour. Caesarean section and gestation at birth were adjusted where relevant. Adjustments for all outcomes are outlined below the tables. Multivariate regression models were restricted to individuals with no missing values. No inferential statistics were carried out on severe maternal or neonatal morbidity and mortality outcomes due to the small numbers involved. Stata V.12 was used for all analyses.

\section{RESULTS}

Data were obtained for all 3651 eligible women identified. In total, 494 planned to give birth at a freestanding midwifery unit and 3157 planned to give birth at a tertiary-level maternity unit (figure 1). Of the 494 women who planned to give birth at the freestanding midwifery unit 238 women $(48.2 \%)$ gave birth at a tertiary-level maternity unit, 244 women (49.4\%) gave birth at the freestanding midwifery unit as planned, and a further $12(2.4 \%)$ gave birth before admission to the freestanding midwifery unit. Of the 494 women who planned to give birth in a freestanding midwifery unit, $256(51.8 \%)$ transferred to a tertiary-level maternity unit (34\% antenatal, $13.2 \%$ intrapartum, $3.6 \%$ postnatal and $1 \%$ unknown stage of transfer). The majority of women who planned to give birth at a tertiary-level maternity unit actually gave birth there $(98 \%)$, with 28 women $(0.9 \%)$ giving birth before arriving. Thirty-four women $(1.1 \%)$ who intended to give birth at a tertiary-level maternity unit actually gave birth at a freestanding midwifery unit, and four of these women transferred to a tertiary-level maternity unit postnatally.

Table 3 shows the mean age, mean parity, proportion of nulliparous women, ethnicity, smoking status, risk status at booking, risk status at the onset of labour and rates of previous caesarean section by planned place of birth. There was no significant difference in mean parity and proportion of nulliparous women in each group. Women who planned to give birth at a freestanding midwifery unit had a significantly higher mean age, and significantly fewer women from this group smoked, had a risk factor at the onset of labour or had experienced a previous caesarean section compared with women from the tertiary-level maternity unit. There were 27 women from the freestanding midwifery unit group who had a risk factor at the time of booking. Women who identified as an Oceanic ethnicity (representing women born in Australia, New Zealand, Papua New Guinea, Fiji and Western Samoa) made up most of the tertiary-level maternity unit group $(90.5 \%)$, while this ethnicity only represented $70.9 \%$ of the freestanding midwifery unit group.

\section{Primary and secondary maternal outcomes}

Table 4 describes the primary and secondary maternal outcomes and shows the unadjusted ORs and AORs of maternal outcomes by planned place of birth. After adjusting for maternal age, smoking status, parity, risk at the onset of labour, gestation at the time of birth and previous caesarean section, compared with the tertiary cohort, freestanding midwifery unit women were significantly more likely to have a spontaneous vaginal birth (AOR 1.57; 95\% CI 1.20 to 2.06) and significantly less likely to have a caesarean section (AOR 0.65; 95\% CI 0.48 to 0.88 ), including elective caesarean section (AOR 0.50; $95 \%$ CI 0.29 to 0.88$)$. The reduction in the odds of women from the freestanding midwifery unit group having an instrumental delivery or intrapartum caesarean 


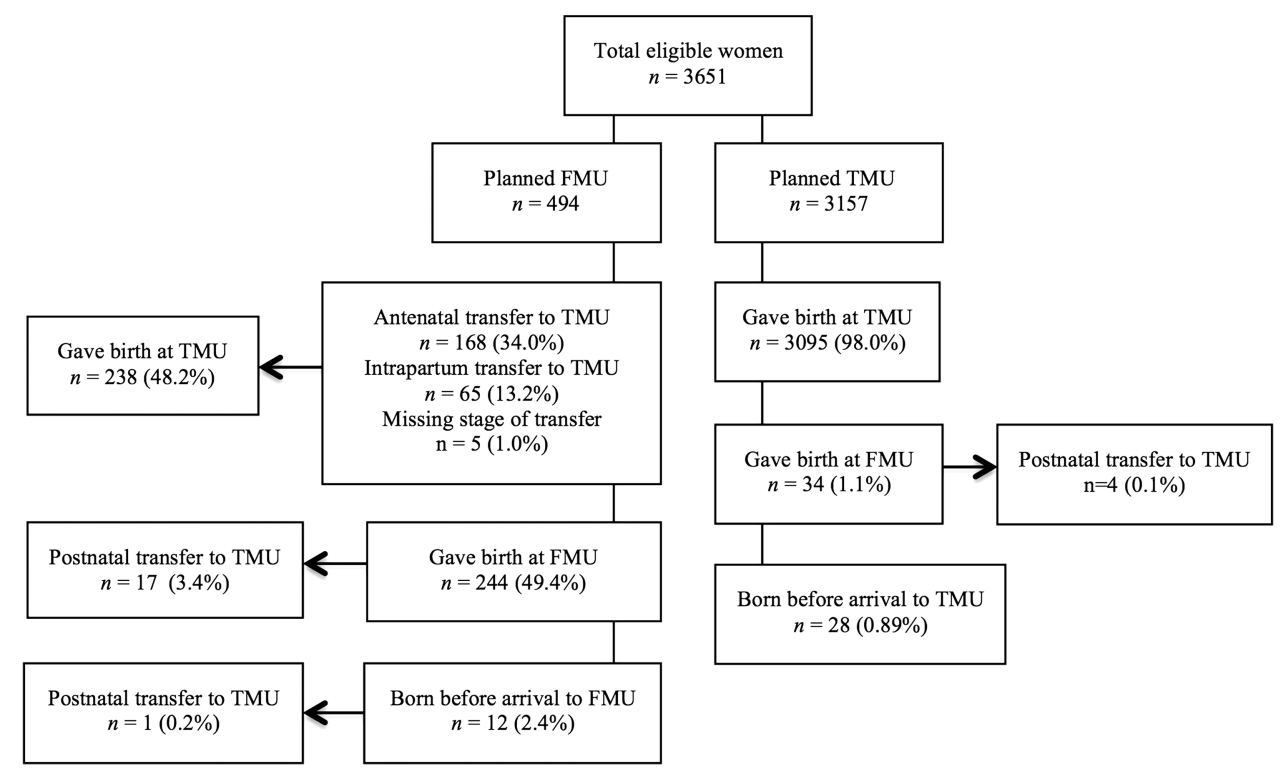

Figure 1 Study population and transfers from freestanding midwifery units (FMU) to tertiary level maternity unit (TMU). Percentages expressed by planned place of birth.

section lost significance when adjusted for confounding factors (AOR 0.79; 95\% CI 0.53 to 1.17 and AOR 0.76; $95 \%$ CI 0.53 to 1.10 , respectively; table 4 ).

After adjusting for confounding factors, women who planned to give birth in a freestanding midwifery unit were twice as likely to have a spontaneous onset of labour (AOR 2.01; 95\% CI 1.60 to 2.54) and significantly less likely to experience: induction (AOR 0.50;95\% CI
0.39 to 0.63 ), augmentation of labour (AOR $0.51 ; 95 \%$ CI 0.38 to 0.67 ) or intramuscular or intravenous narcotic analgesia (AOR 0.26 ; $95 \%$ CI 0.18 to 0.36 ).

Despite the significantly higher odds of physiological management of the third stage of labour among women from the freestanding midwifery unit group (AOR 15.03; $95 \%$ CI 11.05 to 20.43 ), they were significantly more likely to experience blood loss of less than $500 \mathrm{~mL}$

Table 3 Maternal characteristics by planned place of birth

\begin{tabular}{|c|c|c|c|}
\hline Characteristics & $\begin{array}{l}\text { Freestanding } \\
\mathrm{n}=494 \\
\mathrm{~N}(\%)\end{array}$ & $\begin{array}{l}\text { Tertiary } \\
\mathrm{n}=3157 \\
\mathrm{~N}(\%)\end{array}$ & p Value* \\
\hline Mean age & 29.6 & $28.5 \dagger$ & $<0.001$ \\
\hline Median (mean) parity & $1(0.9)$ & $1(1.0)$ & 0.8 \\
\hline Proportion of nulliparae & $208(42.1)$ & 1364 (43.2) & 0.6 \\
\hline \multicolumn{4}{|l|}{ Ethnicity } \\
\hline African & $5(1.0)$ & 40 (1.3) & \multirow[t]{8}{*}{$<0.001$} \\
\hline Asian & $100(20.2)$ & $140(4.4)$ & \\
\hline European & $27(5.5)$ & $92(2.9)$ & \\
\hline Oceania & 350 (70.9) & $2856(90.5)$ & \\
\hline Aboriginal/Torres Strait Islander & $12(3.4) \ddagger$ & 165 (5.8)‡ & \\
\hline South American & $4(0.8)$ & $5(0.2)$ & \\
\hline North American & $7(1.4)$ & $20(0.6)$ & \\
\hline Missing data & $1(0.2)$ & $4(0.1)$ & \\
\hline \multicolumn{4}{|l|}{ Smoking status } \\
\hline Smoker & $27(5.5)$ & $546(17.3)$ & $<0.001$ \\
\hline \multicolumn{4}{|l|}{ Risk at booking } \\
\hline Category $\mathrm{B} / \mathrm{C}$ or $\mathrm{C}$ & $27(5.5)$ & 0 & $\S$ \\
\hline \multicolumn{4}{|l|}{ Risk at onset of labour } \\
\hline Category $\mathrm{B} / \mathrm{C}$ or $\mathrm{C}$ & $65(13.2)$ & $598(18.9)$ & 0.002 \\
\hline Previous caesarean section & $2(0.4)$ & $430(13.6)$ & $<0.0001$ \\
\hline $\begin{array}{l}\text { *Statistically significant results in bold. } \\
\text { †From } n=3156 \text { women. Missing data fr } \\
\text { †Expressed as a percentage of the Oc } \\
\text { §Numbers too small, multivariate mode }\end{array}$ & e corresponding & & \\
\hline
\end{tabular}


Table 4 Maternal outcomes by planned place of birth

\begin{tabular}{|c|c|c|c|c|c|}
\hline Outcome & $\begin{array}{l}\text { Freestanding } \\
\mathrm{n}=494 \\
\mathrm{~N}(\%)\end{array}$ & $\begin{array}{l}\text { Tertiary } \\
\mathrm{n}=3157 \\
\mathrm{~N}(\%)\end{array}$ & $\begin{array}{l}\text { Unadjusted OR } \\
(95 \% \mathrm{Cl})^{\star}\end{array}$ & $\begin{array}{l}\text { Adjusted OR } \\
(95 \% \mathrm{Cl})^{\star} \dagger\end{array}$ & p Value* \\
\hline \multicolumn{6}{|l|}{ Mode of birth } \\
\hline Spontaneous vaginal & $400(81.0)$ & $2044(64.7)$ & 2.32 (1.83 to 2.93$)$ & $1.57(1.20$ to 2.06$) \ddagger$ & 0.001 \\
\hline Instrumental & $34(6.9)$ & 331 (10.5) & $0.63(0.44$ to 0.91$)$ & $0.79(0.53$ to 1.17$) \ddagger$ & 0.237 \\
\hline Caesarean section & $60(12.1)$ & $782(24.8)$ & $0.42(0.32$ to 0.56$)$ & $0.65(0.48$ to 0.88$) \ddagger$ & 0.006 \\
\hline Intrapartum & $40(8.1)$ & $413(13.1)$ & $0.53(0.38$ to 0.74$)$ & $0.76(0.53$ to 1.10$) \ddagger$ & 0.151 \\
\hline Elective & $20(4.0)$ & 369 (11.7) & $0.32(0.20$ to 0.51$)$ & $0.50(0.29$ to 0.88$) \ddagger$ & 0.02 \\
\hline \multicolumn{6}{|l|}{ Labour onset§ } \\
\hline Spontaneous & $378(76.5)$ & $1782(56.4)$ & 2.51 (2.02 to 3.13$)$ & 2.01 (1.60 to 2.54$)$ & $<0.0001$ \\
\hline Induction & 97 (19.6) & 1010 (32.0) & 0.52 (0.41 to 0.66$)$ & 0.50 (0.39 to 0.63$)$ & $<0.0001$ \\
\hline \multicolumn{6}{|l|}{ Labour intervention } \\
\hline Augmentation & $66(13.4)$ & $690(21.9)$ & $0.55(0.42$ to 0.72$)$ & 0.51 (0.38 to 0.67$)$ & $<0.0001$ \\
\hline \multicolumn{6}{|l|}{ Analgesia } \\
\hline Epidural/spinal & $62(12.6)$ & 577 (18.3) & $0.64(0.48$ to 0.85$)$ & $0.87(0.63$ to 1.19$)$ ף & 0.388 \\
\hline Intramuscular/ intravenous narcotic & $38(7.7)$ & $856(27.1)$ & $0.22(0.16$ to 0.31$)$ & $0.26(0.18$ to 0.36$)$ ๆ & $<0.0001$ \\
\hline No analgesia & $115(23.3)$ & $556(17.6)$ & 1.42 (1.13 to 1.78$)$ & $0.92(0.72$ to 1.18$) \emptyset$ & 0.512 \\
\hline \multicolumn{6}{|l|}{ Blood loss (mL) } \\
\hline$<500$ & $428(86.6)$ & 2533 (80.2) & 1.60 (1.22 to 2.10$)$ & $1.37(1.03$ to 1.82$) \ddagger$ & 0.029 \\
\hline 500-999 & $48(9.7)$ & $485(15.4)$ & $0.59(0.43$ to 0.81$)$ & $0.70(0.51$ to 0.97$) \ddagger$ & 0.031 \\
\hline$>1000$ & $18(3.6)$ & $139(4.4)$ & $0.82(0.50$ to 1.35$)$ & $0.88(0.52$ to 1.47$) \ddagger$ & 0.618 \\
\hline \multicolumn{6}{|l|}{ Third stage } \\
\hline Physiological & $185(37.4)$ & $93(2.9)$ & 19.7 (15.0 to 26.0$)$ & 15.03 (11.05 to 20.43$) \ddagger$ & $<0.0001$ \\
\hline \multicolumn{6}{|l|}{ Perineal trauma } \\
\hline None/graze & $241(48.8)$ & $1752(55.5)$ & $0.76(0.63$ to 0.92$)$ & $0.88(0.71 \text { to } 1.10)^{\star \star}$ & 0.275 \\
\hline 1st/2nd degree tear & $229(46.4)$ & $1273(40.3)$ & 1.28 (1.06 to 1.55$)$ & $1.15(0.93 \text { to } 1.42)^{\star \star}$ & 0.210 \\
\hline 3rd/4th degree tear & $24(4.9)$ & $132(4.2)$ & $1.17(0.75$ to 1.83$)$ & $0.90(0.56 \text { to } 1.45)^{\star *}$ & 0.671 \\
\hline \multicolumn{6}{|l|}{ Episiotomy } \\
\hline Episiotomy & $38(7.7)$ & 315 (10.0) & 0.75 (0.53 to 1.07$)$ & 5 to 1.19$)^{\star *}$ & 0.275 \\
\hline Extended to $3 \mathrm{rd} / 4$ th & $7(1.4)$ & 37 (1.2) & $1.2(0.53$ to 2.71$)$ & $1.59(0.67 \text { to } 3.77)^{\star *}$ & 0.292 \\
\hline \multicolumn{6}{|c|}{$\begin{array}{l}\text { *Statistically significant results in bold. } p \text { Values reported for adjusted ORs. } \\
\text { †All adjusted ORs adjusted for maternal age, smoking status, parity, risk at the onset of labour, previous caesarean section and gestation at } \\
\text { the time of birth. } \\
\text { †Also adjusted for augmentation and induction. } \\
\text { §One woman from the freestanding midwifery unit group and four women from the tertiary level maternity unit group went into labour } \\
\text { spontaneously and proceeded to have an elective caesarean section. They were coded as spontaneous and elective caesarean. } \\
\text { †Also adjusted for augmentation and induction. Elective caesarean sections excluded from analysis. } \\
{ }^{*} \text { Also adjusted for augmentation and induction. All caesarean sections excluded from analysis. }\end{array}$} \\
\hline
\end{tabular}

(AOR 1.37; 95\% CI 1.03 to 1.82 ) and significantly less likely to experience blood loss of 500-999 mL (AOR $0.70 ; 95 \%$ CI 0.51 to 0.97 ). There was no significant difference in major postpartum haemorrhage of greater than $1000 \mathrm{~mL}$ (AOR 0.88; $95 \%$ CI 0.52 to 1.47 ; table 4 ).

The AORs of having epidural/spinal analgesia, no analgesia or any type of perineal trauma (including episiotomy extending to third or fourth degree tear) did not differ significantly between settings.

\section{Primary and secondary neonatal outcomes}

Table 5 describes the primary and secondary neonatal outcomes for live born babies and shows the unadjusted ORs and AORs of neonatal outcomes by planned place of birth. Babies from the freestanding midwifery unit group were significantly less likely to be admitted to SCN or NICU (AOR 0.60; $95 \%$ CI 0.39 to 0.91 ; table 5). The reduction in the odds of babies from the freestanding midwifery unit group having an Apgar score of less than 7 at 5 min lost significance when adjusted for confounding factors (AOR $0.57 ; 95 \%$ CI 0.25 to 1.35 ).

After adjusting for known confounders, babies from the freestanding midwifery unit group were significantly more likely to require no resuscitation at birth compared with babies from the tertiary-level maternity unit group (AOR 1.39; 95\% CI 1.04 to 1.85 ). The significance of the higher odds of babies from the freestanding midwifery unit group weighing between 2500 and $4500 \mathrm{~g}$ at birth was borderline (AOR 1.74; 95\% CI 1.00 to 3.03 ) The AORs of being greater than 42 weeks gestation (AOR 4.62; 95\% CI 2.31 to 9.31), being breastfed at birth (AOR 2.38; 95\% CI 1.59 to 3.57 ) or being exclusively breastfed on hospital discharge (AOR 1.59; $95 \%$ CI 1.14 to 2.24) were significantly higher in babies from the freestanding midwifery unit group compared with those from the tertiary-level maternity unit group.

Significantly fewer babies from the freestanding midwifery unit group were less than 37 weeks gestation (AOR 
Table 5 Neonatal outcomes for live births by planned place of birth

\begin{tabular}{|c|c|c|c|c|c|}
\hline Outcome & $\begin{array}{l}\text { Freestanding } \\
\mathrm{n}=490 \\
\mathrm{~N}(\%)\end{array}$ & $\begin{array}{l}\text { Tertiary } \\
\mathrm{n}=3145 \\
\mathrm{~N}(\%)\end{array}$ & $\begin{array}{l}\text { Unadjusted OR } \\
(95 \% \mathrm{Cl})^{\star}\end{array}$ & $\begin{array}{l}\text { Adjusted OR } \\
(95 \% \mathrm{Cl})^{\star} \dagger\end{array}$ & p Value* \\
\hline \multicolumn{6}{|l|}{ Apgar } \\
\hline$<7$ at $5 \mathrm{~min}$ & $6(1.2)$ & $88(2.8)$ & $0.43(0.19$ to 0.99$)$ & $0.57(0.25$ to 1.35$) \ddagger$ & 0.203 \\
\hline \multicolumn{6}{|l|}{ SCN/NICU } \\
\hline Admitted to SCN/NICU & $33(6.7)$ & $432(13.7)$ & $0.45(0.31$ to 0.65$)$ & $0.60(0.39$ to 0.91$) \ddagger$ & 0.017 \\
\hline \multicolumn{6}{|l|}{ Need for resuscitation } \\
\hline Nil & $421(85.9)$ & 2462 (78.3) & 1.69 (1.29 to 2.21$)$ & $1.39(1.04$ to 1.85$) \S$ & 0.027 \\
\hline Suction & $11(2.2)$ & $134(4.3)$ & $0.52(0.28$ to 0.96$)$ & $0.62(0.33$ to 1.17$) \S$ & 0.139 \\
\hline Supplemental oxygen & $13(2.7)$ & $150(4.8)$ & 0.54 (0.31 to 0.97$)$ & $0.73(0.40$ to 1.32$) \S$ & 0.291 \\
\hline IPP (mask) & $43(8.8)$ & $371(11.8)$ & $0.72(0.52$ to 1.00$)$ & $0.80(0.56$ to 1.15$) \S$ & 0.231 \\
\hline IPP (endotracheal tube) & $1(0.2)$ & $25(0.8)$ & $0.26(0.03$ to 1.89$)$ & П & П \\
\hline Cardiac compression & $1(0.2)$ & $3(0.1)$ & $2.14(0.22$ to 20.54$)$ & П & १ \\
\hline \multicolumn{6}{|l|}{ Birth weight $(\mathrm{g})$} \\
\hline$<2500$ & $9(1.8)$ & $176(5.6)$ & $0.32(0.16$ to 0.62$)$ & $0.38(0.16$ to 0.89$) \ddagger$ & 0.026 \\
\hline $2500-4500$ & $472(96.3)$ & 2899 (92.2) & 2.26 (1.37 to 3.63$)$ & $1.74(1.00$ to 3.03$) \ddagger$ & 0.050 \\
\hline$>4500$ & $9(1.8)$ & $70(2.2)$ & $0.82(0.41$ to 1.66$)$ & $0.77(0.37$ to 1.58$) \ddagger$ & 0.473 \\
\hline \multicolumn{6}{|l|}{ Gestational age } \\
\hline$<37$ & $14(2.9)$ & $202(6.4)$ & $0.43(0.25$ to 0.74$)$ & $0.53(0.29 \text { to } 0.96)^{\star \star}$ & 0.035 \\
\hline $37-41$ & $461(94.1)$ & 2913 (92.6) & $1.27(0.85$ to 1.89$)$ & $0.95(0.61 \text { to } 1.47)^{\star \star}$ & 0.810 \\
\hline $42-43$ & $15(3.1)$ & $30(1.0)$ & $3.28(1.75$ to 6.14$)$ & $4.62(2.31 \text { to } 9.31)^{\star \star}$ & $<0.0001$ \\
\hline \multicolumn{6}{|l|}{ Breastfeeding } \\
\hline Breastfed at birth & 460 (93.9) & 2604 (82.8) & 3.19 (2.18 to 4.66$)$ & 2.38 (1.59 to 3.57$) \dagger †$ & $<0.0001$ \\
\hline Exclusive on discharge $\ddagger \ddagger$ & 447 (91.22) & 2586 (82.23) & 2.10 (1.53 to 2.87$)$ & $1.59(1.14$ to 2.24$) \dagger \dagger$ & 0.007 \\
\hline \multicolumn{6}{|c|}{ 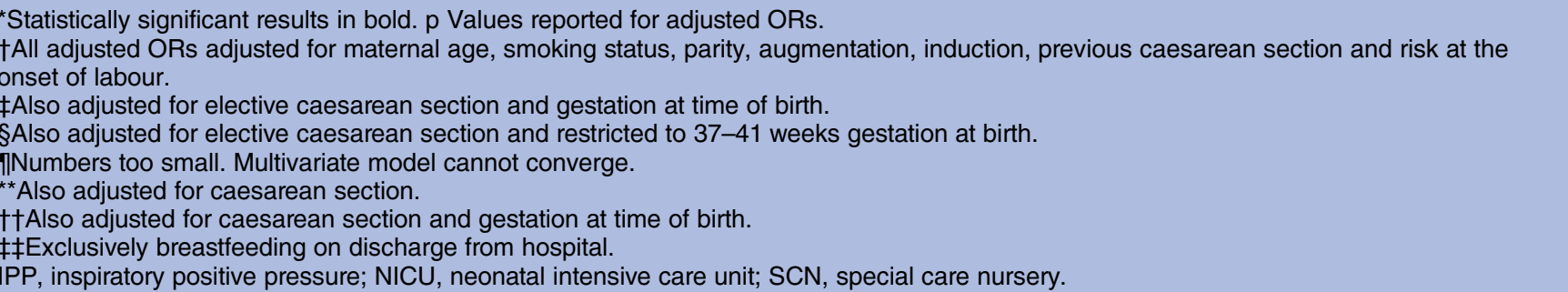 } \\
\hline
\end{tabular}

$0.53,95 \%$ CI 0.29 to 0.96$)$ or had a birth weight of less than $2500 \mathrm{~g}$ (AOR $0.38,95 \%$ CI 0.16 to 0.89 ). The AORs of babies requiring resuscitation at birth in the form of suction, supplemental oxygen or inspiratory positive pressure (with mask or endotracheal tube), or being between 37 and 41 weeks gestation at birth showed no significant difference between the two groups (table 5).

Severe neonatal morbidity was defined as 5 min Apgar score of less than 7 followed by admission to NICU/SCN. This affected three babies from the freestanding midwifery unit group and 46 babies from the tertiary-level maternity unit group (figure 2). One of these babies from the tertiary-level maternity unit group subsequently died and two were transferred to another hospital.

There were a total of 31 perinatal deaths during the study period. Sixteen $(0.44 \%)$ babies were stillborn, four of these infants were born in a tertiary-level maternity unit following antenatal transfer from a freestanding midwifery unit, and 12 were in the tertiary-level maternity unit group. Fifteen $(0.41 \%)$ neonatal deaths occurred in the tertiary-level maternity unit group. Online supplementary information on perinatal mortality by planned place of birth is provided in tables $A$ and $B$.
Online supplementary table C describes severe maternal morbidity by planned place of birth. One caesarean section (and hysterectomy) was carried out at the nearest general hospital to a freestanding midwifery unit owing to maternal collapse due to a suspected amniotic fluid embolism. The woman and her baby were transferred to a non-referral tertiary hospital immediately post partum. Five women from the tertiary-level maternity unit group had a hysterectomy following postpartum haemorrhage of greater than $1000 \mathrm{~mL}$, and one of these women was transferred to another hospital during the postnatal period.

\section{DISCUSSION}

Women who planned to give birth at freestanding midwifery units were significantly more likely than women who planned to give birth at tertiary-level maternity units to have a spontaneous vaginal birth and significantly less likely to have a caesarean section. The subgroups of caesarean section produced different results. Women from the freestanding midwifery unit group were significantly less likely to have an elective caesarean section, and the adjusted odds of requiring an intrapartum caesarean 


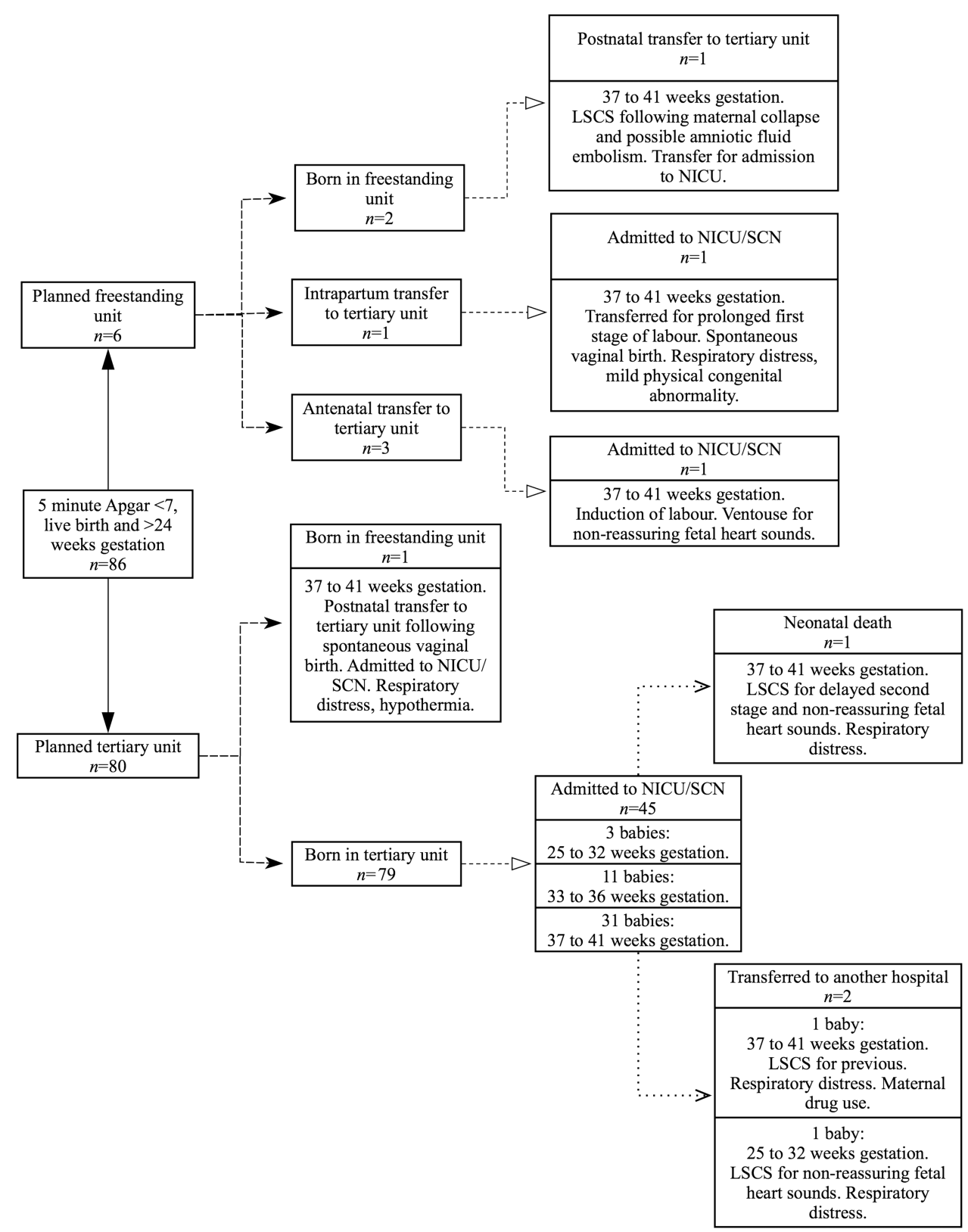

Figure 2 Severe neonatal morbidity: babies with a 5 min Apgar score of less than 7 followed by admission to NICU/SCN (restricted to live born babies greater than 24 weeks gestation). LSCS, lower segment caesarean section; NICU, neonatal intensive care unit; SCN, special care nursery.

section were not significant. Not surprisingly, the most predictive variable for caesarean section (including intrapartum and elective caesarean section) was having a 'previous caesarean section'. Infants of women from the freestanding midwifery unit group were significantly less likely to be admitted to SCN/NICU. Similar rates were observed for Apgar score of less than 7 at $5 \mathrm{~min}$.

With regard to secondary outcomes, women who planned to give birth at freestanding midwifery units were significantly more likely than women who planned to give birth at tertiary-level maternity units to have a spontaneous onset of labour, estimated postpartum blood loss of less than $500 \mathrm{~mL}$ or physiological management of third stage of labour. They were significantly less likely to have an induction or augmentation of labour, intramuscular/intravenous analgesia or an estimated blood loss of between 500 and $1000 \mathrm{~mL}$. The babies of women who planned to give birth at freestanding midwifery units were significantly more likely than the babies of women who planned to give birth at tertiary-level maternity units to require no resuscitation at birth, weigh between 2500 and $4500 \mathrm{~g}$ at birth, be greater than 42 weeks gestation at the time of birth, be breastfed at birth or exclusively breastfed on hospital discharge. They were significantly less likely to weigh less than $2500 \mathrm{~g}$ at birth or to be less than 37 weeks gestation.

This is the first prospective cohort study of maternal and neonatal outcomes among women who planned to 
give birth in freestanding midwifery units in Australia. Selection bias was minimised by prospectively identifying women's planned place of birth at booking and analysing the outcomes according to the place where women intended to give birth. The use of a population database ensured that there was a minimal loss to follow-up and minimal bias introduced due to a non-response rate. All women who planned to give birth at a freestanding midwifery unit were included in the study, regardless of identified risks at booking. In this way the outcomes reflect the current practice and function of freestanding midwifery units in Australia. The study ensured comparability of the cohorts of women by rigorously judging the tertiary-level maternity unit group at booking to be at low risk of developing obstetric complications, and also by controlling for risk at the onset of labour during analysis.

The study is limited because it was not possible to randomly assign women to one or other maternity unit and system of care, therefore leaving a potential for selection bias. In particular, the subtle differences that may exist between women who plan to give birth where there is no specialised medical support on site and those who choose to go to a tertiary-level maternity unit cannot be quantified. Thirty-four women from the tertiary-unit group crossed over to give birth in the freestanding midwifery unit group, although these women represented less than $1 \%$ of the study population. These factors, along with not controlling for BMI and socioeconomic status, may have had a bearing on some of the outcome measures. Selecting a prospective comparative reference cohort from the referral hospitals and analysing the data according to the place where women intended to give birth went some way in addressing the selection bias at the design stage.

A further limitation of the study was the inability to retrieve data on severe morbidity recorded in databases other than the one available for the study. As a result this study could not provide the level of information relating to more complex measures of maternal and perinatal morbidity as employed in other studies. ${ }^{19} 2228$ This reflects the fragmented nature of routine maternity information system databases.

No inferential statistics were applied to some measures because of small numbers; however, the detailed reporting of adverse and rare events strengthened the study. The crude number of rare outcomes in this study is surprising. First, an amniotic fluid embolism that was not preceded by an induction of labour is extremely rare. The reported incidence of amniotic fluid embolism in high-resource countries ranges from 1.9 to 6.1 cases/ 100000 births, ${ }^{29}$ with induction of labour being a highly significant risk factor. ${ }^{30}$ Given the high fatality rate for this condition, it is notable that the woman found to have an amniotic fluid embolism survived and was able to be transferred to a tertiary-level hospital.

Second, the incidence of postpartum haemorrhage followed by hysterectomy in this study $(1.64 / 1000$ births) is relatively high compared with results from a large population-based cohort study in America (0.48/1000 births). ${ }^{31}$ Five of the six cases of postpartum haemorrhage followed by hysterectomy were in women who had a repeat caesarean section, and three of these women had placenta praevia or accreta. There is conflicting evidence on the association between repeat caesarean section and postpartum haemorrhage, ${ }^{32}$ with evidence pointing towards no association between the two. ${ }^{33} 34$ A causative link has been established between repeat caesarean sections and placenta accreta and hysterectomy; ${ }^{35-37}$ however, there is the possibility of other causative influences for placenta accreta such as surgical technique. ${ }^{36}{ }^{38}$ Further research into the incidence and prevalence of severe morbidity among childbearing women is needed, and is already underway in Australia through the Australasian Maternity Outcomes Surveillance System (AMOSS). AMOSS is a national surveillance mechanism designed to study a variety of rare or serious conditions during the antenatal, intrapartum and postnatal periods. ${ }^{39}$

Generalisation of these findings should be undertaken with caution given that there are very few freestanding midwifery units in Australia. Owing to their rarity in Australia there are no nationally recognised guidelines and referral pathways specific to freestanding midwifery units other than the general guidelines designed by the ACM. ${ }^{27}$ The midwives who provide care in the units in this study are highly skilled and have formally integrated networking relationships with their referral tertiary-level maternity units through which they have the support of obstetric teams. ${ }^{13}$ The findings may not apply to other maternity units that do not offer the same care, referral pathways and distance to tertiary referral hospitals.

In addition, giving birth in any maternity setting brings with it a unique set of complexities and relationships, which impact on outcomes for women and their infants. ${ }^{40}$ Women who plan to give birth outside the conventional tertiary hospital setting may choose to do so for various reasons. The impact these characteristics have on birth outcomes are unknown and outside the scope of this paper. Further analysis of women's selfreported rationale for choosing a freestanding midwifery unit, or not, will add further detail to these findings. ${ }^{41}$

The research findings agree with important large studies undertaken recently overseas including the UK, ${ }^{19}$ Scandinavia ${ }^{22}$ and New Zealand, ${ }^{21}$ which found that planning to give birth in a freestanding midwifery unit was associated with a reduced risk of having a caesarean section and either no difference or a reduction in the odds of neonatal morbidities. ${ }^{19} 2122$ This study found similar rates of maternal and neonatal outcomes for low-risk women reported in a previous Australian population-based study to determine disadvantages associated with giving birth in low volume maternity hospitals. ${ }^{18}$ Looking at neonatal mortality, the overall rates of stillbirth in this study $(0.44 \%)$ were lower than all maternity units in Tracy et $a l \mathrm{~s}^{18}$ study, which reported rates of stillbirth between $0.49 \%$ for hospitals with between 100 
and 500 births per annum and $0.94 \%$ for hospitals with greater than 2000 births per annum. The rate of neonatal deaths in this study $(0.41 \%)$ were lower than those reported for hospitals of comparable size $(0.56 \%){ }^{18}$ The proportion of low birthweight babies in both cohorts in this study (1.8\% in the freestanding group and $5.6 \%$ in the tertiary group) was relatively low compared with the incidence of low birthweight babies in Australian maternity units with between 100 and 500 births per year $(4.04 \%)$ and in maternity units with greater than 2000 births per year $(9.77 \%) .{ }^{18}$

The overall rate of transfer in this study (51.8\%) appears high when compared with the two recent cohort studies on freestanding midwifery units. ${ }^{19} 22$ However, the current study is unique in that it reports rates of antenatal transfer (34\%). Both freestanding units studied have a strong collaborative relationship with their tertiary referral units and women and midwives are encouraged to err on the side of caution and transfer antenatally whenever there is a possibility that medical intervention may be required during the birth process. Comparable rates of antenatal transfer were reported in randomised controlled trials on alongside midwife-led units in Ireland $^{42}(45 \%)$ and Scotland ${ }^{43}$ $(38 \%)$. The rates of intrapartum/postnatal transfer from this study $(16.8 \%)$ sit between the intrapartum/postnatal transfer rates from freestanding midwifery units reported by Overgaard et $a t^{22}(16.3 \%)$ and the Birthplace in England Collaborative Group ${ }^{19}(21.9 \%)$.

As a model, the freestanding midwifery unit is a growing and sustainable phenomenon in many countries, including in rural areas, where they are a valuable feature of the publically funded maternity system. ${ }^{21} 4445$ The centralisation of maternity services in Australia has led to the closure of many smaller maternity units, which has left a gap in accessible maternity care. Some freestanding midwifery units have filled this gap in urban and regional areas, however, the lack of accessible maternity services in rural and remote regions of Australia continues to have widespread implications for women and their families. ${ }^{6} 104647$ The challenge facing maternity services today is how to balance the need for safety with the need for equal access to maternity services, including to primary level birth facilities such as freestanding midwifery units.

This study supports the provision of care in freestanding midwifery units as an alternative to tertiary level maternity units for women with low-risk pregnancies at the time of booking. Clinicians and policy makers may find these results useful in the planning and preservation of maternity services in areas where midwifery-only care is available in freestanding midwifery units. There is also scope for the development of standardised national protocols on freestanding midwifery units to improve the transparency of transfers and support the processes of development and evaluation. Further investigation into complex and longer term measures of perinatal morbidity, transfer and the viability of freestanding midwifery units in rural/remote settings is required.

\section{Author affiliations}

${ }^{1}$ Faculty of Nursing and Midwifery, The University of Sydney, Sydney, New South Wales, Australia

${ }^{2}$ Centre for Newborn Care, Westmead Hospital and The University of Sydney, Sydney, New South Wales, Australia

${ }^{3}$ Centre for Midwifery, Child and Family Health, Faculty of Health, The University of Technology Sydney, Sydney, Australia

${ }^{4}$ Centre for Midwifery \& Women's Health Nursing Research Unit, The Royal Hospital for Women and the University of Sydney, Sydney, Australia

Acknowledgements The authors thank the midwives, managers, physicians and data custodians at the participating maternity units for their advice and cooperation.

Contributors ST was the chief investigator of the Evaluating Midwifery Units study, and led its design and coordination. ST, AM, CG, MT and MF were involved in the design of the study. CG was responsible for coordinating the New Zealand arm of the study. MT conducted data analysis and provided statistical advice. AM, ST and MT were involved in interpreting the data. AM was responsible for coordinating the Australian arm of the study, including data collection, cleaning of the data, data analyses and interpretation. She drafted the manuscript and wrote the final version. All authors critically revised the manuscript, provided comment and approved the final version for publication.

Funding The Evaluating Midwifery Units study was funded by the National Health and Medical Research Council of Australia ((NHMRC) Evaluating Maternity Units-Grant Application Number 571901). The grant wholly supported the study for a period of 3 years. The NHMRC did not have a role in the study design, in the collection, analysis or interpretation of the data, the writing of the report or the decision to submit this article for publication.

\section{Competing interests None.}

Ethics approval The study was approved by the Northern Sydney Local Health District Ethics Committee, the Hunter New England Human Research Ethics Committee and The University of Sydney Human Research Ethics Committee (NSW HREC reference number: HREC/09/HNE/78).

Provenance and peer review Not commissioned; externally peer reviewed.

Data sharing statement No additional data are available.

Open Access This is an Open Access article distributed in accordance with the Creative Commons Attribution Non Commercial (CC BY-NC 4.0) license, which permits others to distribute, remix, adapt, build upon this work noncommercially, and license their derivative works on different terms, provided the original work is properly cited and the use is non-commercial. See: http:// creativecommons.org/licenses/by-nc/4.0/

\section{REFERENCES}

1. Centre for Epidemiology and Evidence. New South Wales Mothers and Babies 2010. Sydney: NSW Ministry of Health, 2012.

2. NSW Health Department. Guide to the role delineation of health services: core services-maternity and child health services. Statewide Services Development Branch, 2002.

3. NSW Health Department. Models of maternity service provision across NSW: progressing implementation of the NSW framework for maternity services. North Sydney: NSW Health Department, 2003.

4. Laws PJ, Lim C, Tracy S, et al. Characteristics and practices of birth centres in Australia. Aust N Z J Obstet Gynaecol 2009;49:290-5.

5. Walsh D, Downe SM. Outcomes of free-standing, midwife-led birth centers: a structured review. Birth 2004;31:222-9.

6. Monk AR, Tracy S, Foureur M, et al. Australian primary maternity units: past, present and future. Women Birth 2013;26:213-18.

7. Lane K. When is collaboration not collaboration? When it's militarized. Women Birth 2012;25:29-38.

8. Hambleton S. AMA Parliamentary Dinner Speech, 22 August 2012 http://ama.com.au/media/dr-hambleton-ama-parliamentary-dinnerspeech-22-august-2012 (accessed 1 Jul 2014). 
9. Australian Medical Association. Medical supervision key to safe maternity services. http://ama.com.au/node/3391 (accessed 1 July 2014).

10. Kildea S, Kruske S, Barclay L, et al. 'Closing the Gap': how maternity services can contribute to reducing poor maternal infant health outcomes for Aboriginal and Torres Strait Islander women. Rural Remote Health 2010;10:1-18.

11. Benoit $\mathrm{C}$, Zadoroznyj $\mathrm{M}$, Hallgrimsdottir $\mathrm{H}$, et al. Medical dominance and neoliberalisation in maternal care provision: the evidence from Canada and Australia. Soc Sci Med 2010;71:475-81.

12. Tracy SK, Hartz D, Nicholl M, et al. An integrated service network in maternity - the implementation of a midwifery-led unit. Aust Health Rev 2005;29:332-9.

13. Tracy S, Hartz D. Quality review of the Ryde midwifery caseload practice-a primary level maternity service at Ryde Hospital. September 2004 to October 2005. Sydney: Northern Sydney and Central Coast Health, 2006.

14. Shaw R, Saxton A, Hastie C. Belmont Birthing Service: evaluation and clinical outcomes. Unpublished report: Belmont Birthing Service, 2006.

15. NSW Health Department. Critical care tertiary referral networks (perinatal). North Sydney: Ministry of Health, 2010.

16. Centre for Epidemiology and Research-NSW Health Department New South Wales mothers and babies 2005. N S W Public Health Bull 2007;18:1-135.

17. Walsh $D$. Subverting the assembly-line: childbirth in a free-standing birth centre. Soc Sci Med 2006;62:1330-40.

18. Tracy $\mathrm{S}$, Sullivan $\mathrm{E}$, Dahlen $\mathrm{H}$, et al. Does size matter? A populationbased study of birth in lower volume maternity hospitals for low risk women. BJOG 2006;113:86-96.

19. Birthplace in England Collaborative Group. Perinatal maternal outcomes by planned place of birth for healthy women with low risk pregnancies: the Birthplace in England national prospective cohort study. BMJ 2011;343:1-13.

20. Davis D, Baddock S, Pairman S, et al. Risk of severe postpartum hemorrhage in low-risk childbearing women in New Zealand: exploring the effect of place of birth and comparing third stage management of labor. Birth 2012;39:98-105.

21. Davis D, Baddock S, Pairman S, et al. Planned place of birth in New Zealand: does it affect mode of birth and intervention rates among low-risk women? Birth 2011;38:111-19.

22. Overgaard C, Moller A, Fenger-Gron M, et al. Freestanding midwifery unit versus obstretic unit: a matched cohort study of outcomes in low-risk women. BMJ Open 2011;2:1-11.

23. Schroeder E, Petrou S, Patel N, et al. Cost effectiveness of alternative planned places of birth in woman at low risk of complications: evidence from the Birthplace in England national prospective cohort study. BMJ 2012;344:1-13.

24. Gallo V, Egger M, McCormack V, et al. STrengthening the Reporting of OBservational studies in Epidemiology-Molecular Epidemiology STROBE-ME: an extension of the STROBE statement. J Clin Epidemiol 2011;64:1350-63.

25. Monk AR, Tracy SK, Foureur M, et al. Evaluating midwifery units (EMU): lessons from the pilot study. Midwifery 2013;29:845-51.

26. NSW Department of Health. Critical Care Tertiary Referral Networks \& Transfer of Care (Adults). Statewide Services Department, 2010. (Reviewed 2013)

27. Australian College of Midwives. National Midwifery Guidelines for Consultation and Referral. 2013.

28. Homer C, Thornton C, Scarf V, et al. Birthplace in New South Wales, Australia: an analysis of perinatal outcomes using routinely collected data. BMC Pregnancy Childbirth 2014;14:1-12.
29. Knight $\mathrm{M}$, Berg C, Brocklehurst $\mathrm{P}$, et al. Amniotic fluid embolism incidence, risk factors and outcomes: a review and recommendations. BMC Pregnancy Childbirth 2012;12:7.

30. Kramer MS, Abenhaim H, Dahhou M, et al. Incidence, risk factors, and consequences of amniotic fluid embolism. Paediatr Perinat Epidemiol 2013;27:436-41.

31. Kramer MS, Berg C, Abenhaim $\mathrm{H}$, et al. Incidence, risk factors, and temporal trends in severe postpartum hemorrhage. Am J Obstet Gynecol 2013;209:449.e1-7.

32. Knight M, Callaghan WM, Berg C, et al. Trends in postpartum hemorrhage in high resource countries: a review and recommendations from the International Postpartum Hemorrhage Collaborative Group. BMC Pregnancy Childbirth 2009;9:55.

33. Haynes K, Stone C, King J. Major morbidities associated with childbirth in Victoria: obstetric haemorrhage and associated hysterectomy. Melbourne: Victorian Government Department of Human Services, 2004.

34. Burrows L, Meyn L, Weber A. Maternal morbidity associated with vaginal versus cesarean delivery. Obstet Gynecol 2004; 103:907-12.

35. Silver RM. Implications of the first cesarean: perinatal and future reproductive health and subsequent cesareans, placentation issues, uterine rupture risk, morbidity, and mortality. Semin Perinatol 2012;36:315-23.

36. Higgins MF, Monteith C, Foley M, et al. Real increasing incidence of hysterectomy for placenta accreta following previous caesarean section. Eur J Obstet Gynecol Reprod Biol 2013;171:54-6.

37. Daltveit $\mathrm{A}$, Tollanes $\mathrm{M}$, Pihlstrom $\mathrm{H}$, et al. Cesarean delivery and subsequent pregnancies. Obstet Gynecol 2008;111:1327-34.

38. Sholapurkar SL. Increased incidence of placenta praevia and accreta with previous caesareans-a hypothesis for causation. J Obstet Gynaecol 2013;33:806-9.

39. Halliday LE, Peek MJ, Ellwood DA, et al. The Australasian Maternity Outcomes Surveillance System: an evaluation of stakeholder engagement, usefulness, simplicity, acceptability, data quality and stability. Aust N Z J Obstet Gynaecol 2013;53:152-7.

40. Sinni SV, Wallace EM, Cross WM. Patient safety: a literature review to inform an evaluation of a maternity service. Midwifery 2011;27: e274-8.

41. Grigg C, Tracy SK, Daellenbach R, et al. An exploration of influences on women's birthplace decision-making in New Zealand: a mixed methods prospective cohort within the Evaluating Maternity Units study. BMC Pregnancy Childbirth 2014;14:210.

42. Begley C, Devane D, Clarke M. An evaluation of midwifery led care in the Health Service Executive North Eastern Area. The report of the MidU study. Dublin: Trinity College, 2009.

43. Hundley V, Cruikshank F, Lang G, et al. Midwife managed delivery unit: a randomised controlled comparison with consultant led care. BMJ 1994;309:1400-4.

44. Quinn E, Noble J, Seale $\mathrm{H}$, et al. Investigating the potential for evidence-based midwifery-led services in very remote Australia: viewpoints from local stakeholders. Women Birth 2013;26:254-9.

45. Van Wagner V, Osepchook C, Harney E, et al. Remote midwifery in Nunavik, Quebec, Canada: outcomes of perinatal care for the Inuulitsivik health centre, 2000-2007. Birth 2012;39:230-7.

46. Dietsch E, Martin T, Shackleton $\mathrm{P}$, et al. Australian Aboriginal kinship: a means to enhance maternal well-being. Women Birth 2011;24:58-64.

47. Dietsch E, Shackleton P, Davies C, et al. 'Mind you, there's no anaesthetist on the road': women's experiences of labouring en route. Rural Remote Health 2010;10:1-9. 